\title{
Computer Aided Design and Simulation of Radial Fatigue Test of Automobile Rim Using ANSYS
}

\author{
Emmanuel M. Adigio and Ebughni O. Nangi \\ Niger Delta University \\ Department of Mechanical/Marine EngineeringWilberforce Island, Bayelsa State, Nigeria
}

\begin{abstract}
A finite element based method is used to simulate the radial test of an automobile wheel. Besides the certainty of results obtain through practical, computer aided simulation of the wheel, using ANSYS replicates the actual experiments. The fatigue life limit factors introduced by other researchers were used to obtain the stress and fatigue reduction factors which were further used to estimate the $S$ - $N$ curve as the stress-Life method is employed in predicting the fatigue life of a rim.During the static analysis of the steel wheel, it was discovered that the maximum stress concentration $\left(\sigma_{\max }\right)$ occurred at the spokes and ventilation hole of the rim under loads, Fr and pi. It was observed that when the wheel rotates at a speed of 1790 rpm under the stated loads, the fatigue crack propagates at the point of maximum stress concentration.
\end{abstract}

Keywords: Finite Element analysis, ANSYS, Stress-life, Static analysis, Car rims, Fatigue, Stress concentration, Solidworks

\section{Introduction}

The wheel is a critical component in the automobile and bears the weight of the car as well as helps the tire to maintain contact between the car and the road. The wheel is exposed to very hazardous environmental conditions. For high and optimal performance, the wheel is designed to meet some safety and engineering criteria. The wheel should be able to withstand the impact of shock and vibrations and be able to bear the weight of the car and the passengers; it should be light in weight but highly durable.

To this effect, the wheel undergoes various tests during manufacturing to ensure that quality wheels that can perform effectively are introduced to the market. Three main wheel tests are used in wheel development and design. These are the: rotating bending test, radial fatigue test, and impact test. They are used to test a prototype wheel for various fatigue and durability considerations.

Fatigue fracture, like yielding, is due to formations of cracks at the microscopic level and lengthened by continued applications of stress. It differs however in the manner the stress is applied. Fatigue fracture is instigated by cyclical stresses on the material, which occurs as a result a process of crack nucleation and preexistent cracks in a material [1].

The stress instigated during cyclical stress is mostly sinusoidal in nature that is varying with a specific frequency of stress application [2]. Each peak is denoted as either the maximum stress $\sigma_{\max }$ or minimum stress $\sigma_{\min }$ which are equal and opposite in sign (tension and compression respectively). The applied stress can be torsional, tensile, or flexural in nature.

Some researchers[3] proposed a biaxial notch strain approximation for proportional loading which was used to estimate the fatigue life of a passenger car wheel during the cornering fatigue test under plane stress conditions. They reported that the analytical results obtained from a computer programme compared to actual test results from the cornering fatigue showed encouraging values.

$\mathrm{Lu}$ and Wei [4] used the Cosmos software to build a static load finite element model of bus aluminium HS6061T6 rims which was used to simulate the rotary fatigue test. The results showed that the rim life cycle was improved to over $1.0 \times 105$, indicating that the proposed method of finite element analysis was a good and efficient method to predict the fatigue life of the aluminium rims.

Other researchers [5] used the ABAQUS software to build a static load finite element model of aluminium wheels for simulating the rotary fatigue test. They reported that the results from the aluminium wheel rotary fatigue bench test showed that the failure and its crack initiation was around the hub bolt hole area that agreed with the simulation.

The present work presents a clear method of modeling the automobile rim using Solidworks and a systematic simulation of the stress, bending and radial fatigue test of the rim. 


\section{II.1. STATIC STRESS ANALYSIS}

\section{Analysis}

To obtain the fluctuating stress a static stress analysis is conducted. The stress distribution on the wheel is due to the radial test load $(\mathrm{Fr})$ and the predicted tire pressure $(\mathrm{Pi})$. It was reported that fatigue stress obtain from static stress analysis is reliable [6]. In this work ANSYS Workbench is used for this static analysis.

\section{II.1.1. Rim Size Designation And Cad Model}

The wheel specification is as summarized in Table 1. The mathematical model here refers to the CAD model of the rim. For better analysis, the wheel is modeled using a CAD software, Solidworks, using different features ranging from revolve features, sweep features, extrude boss base and extrude cut, fillet and surface features. To model the wheel a picture sketch was used. This was to ensure that the actual shape of the rim is used while modeling so as to reduce errors.

Figure1 is the CAD model of the rim.

Table 1.Automobile wheel specification

\begin{tabular}{clc}
\hline S/No & \multicolumn{1}{c}{ Specification } & Value \\
\hline 1 & Rim Width & $215.9 \mathrm{~mm}$ \\
2 & Wheel Diameter & $480 \mathrm{~mm}$ \\
3 & Offset & $128 \mathrm{~mm}$ \\
4 & Pitch Circle Diameter(P.C.D) & $110 \mathrm{~mm}$ \\
5 & Centre Base Diameter (CBD) & 70 \\
6 & Rim thickness & 7 \\
7 & Bolt diameter & 10 \\
8 & Number of bolt holes & 5 \\
9 & Ventilation holes diameter & 60 \\
10 & material & $5335 \mathrm{MC}$ alloy steel \\
11 & Manufacturing process & Flow forming process \\
\hline
\end{tabular}

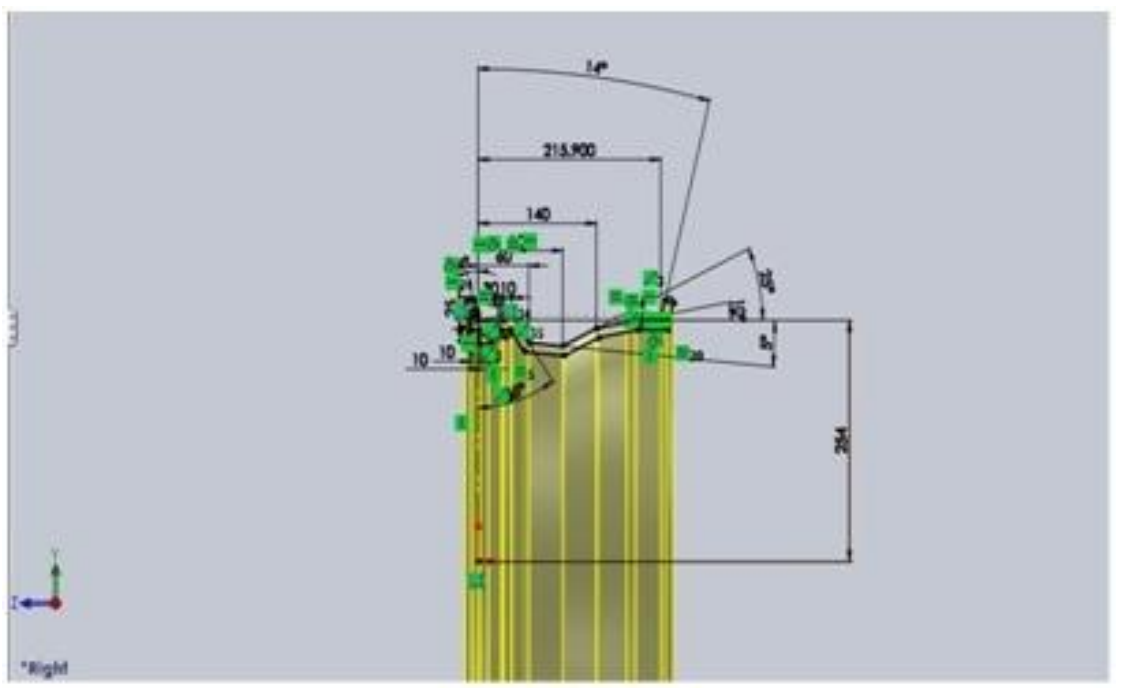

Figure 1.Solidworks production of the Automobile Rim

\subsubsection{Preprocessor Stage of Static Study}

The mathematical modeling was established by importing the CAD file of the rim that was modeled with Solidworks to ANSYS workbench. The data, rim material specification, was inputted andall necessary editions were made. The CAD model of the rim was then imported to ANSYS as an IGES file format. TheCAD model and data input is shown in Figure 2. 

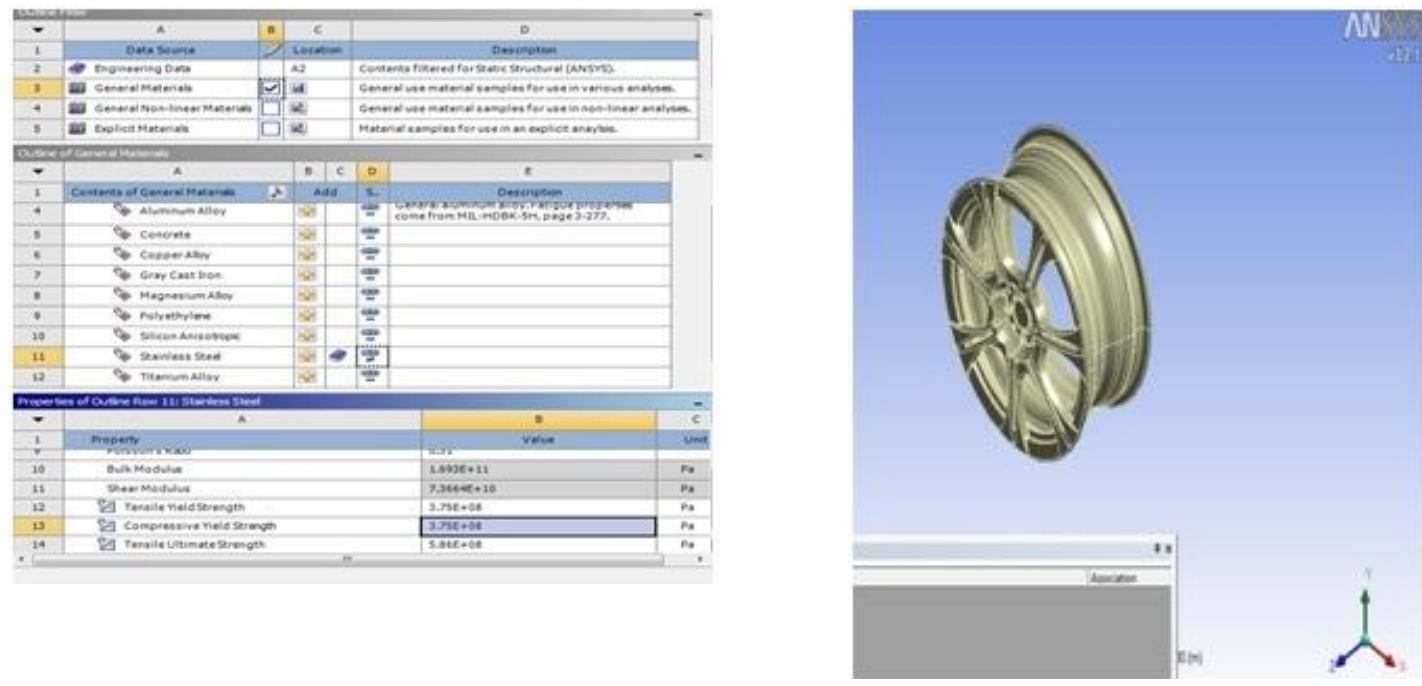

Figure 2.Material properties and Cad Model of the Rim

\subsubsection{Discretization of the Mathematical Model}

The ANSYS workbench uses a finite element method to discretize the model into finite elements. Finer mesh size was used; a mesh size of $10 \mathrm{~mm}(0.01 \mathrm{~m})$. SOLID 18710 node tetrahedral is the element used for the analysis. The element is defined by 10 nodes having three degrees of freedom at each node: translations in the nodal $\mathrm{x}, \mathrm{y}$, and $\mathrm{z}$ directions. In meshing the rim, a smooth transition inflation option is used, with transition ratio of 0.272 and growth rate of 1.2. A total of nodes and elements are created for this mesh. A patch conforming method is also used. Figure 3 shows a discretized rim from the ANSYS workbench.

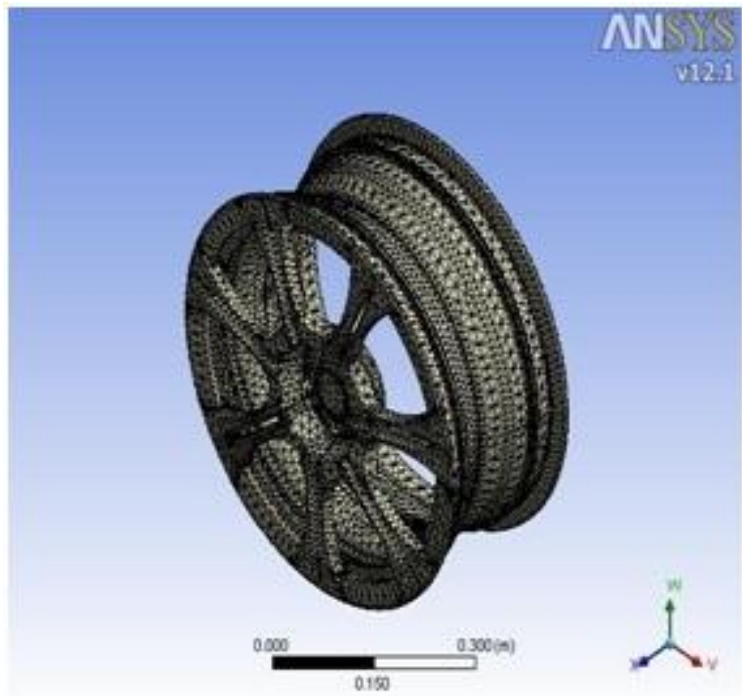

\subsubsection{Boundary Conditions}

Figure 3. Discretize (Mesh Model) of the rim

In the experimental set-up used in the industry that is been mimicked by this simulation, two boundary conditions were applied. These initial boundary conditions are the number of degree of freedom (DOF) at the holes where the rim is assembled to the axle and the force tending to turn the rim and the inflation pressure from the tire.

The driven drum exacts a radial test load (Fr) on the wheel assembly during rotation while the tire exacts a predicted air pressure $(p i)$ on the rim flanges. According to the Association of European Wheel manufactures (EUWA) and the Society of Automotive Engineers (SAE), the radial test load ( $\mathrm{Fr}$ ) is computed as follows [8]:

$F_{r}=k \cdot F_{v} \cdot g[N]$ 1

where

$F_{r}$ is the radial test load, $F_{v}$ is the nominal or maximum design load of the wheel which is equal to $570 \mathrm{kgf}$ for this specific wheel design [7],kis the accelerated test load factor which is given as 2.2 .

To calculate for $\mathrm{F}_{\mathrm{r}}$, using the values for $\mathrm{F}_{\mathrm{v}}$ andk as estimated in Table $2, F_{r}=2.2 \times 570 \times 9.81=12301 \mathrm{~N}$

The predicted air tire inflation pressure ( $p i)$ was used as $303.4 \mathrm{KPa}$ (which is an ideal tire gauge pressure for vehicle steel wheels according EUWA[8]. 
Table 2.Summary of Parameters used for the Static Study

\begin{tabular}{clll}
\hline S/No & \multicolumn{1}{c}{ Parameters } & \multicolumn{1}{c}{ Symbols } & \multicolumn{1}{c}{ Data } \\
\hline 1 & Radial test load & Fr & $12301.74 \mathrm{~N}$ \\
2 & Wheel design load & Fv & $570 \mathrm{kgf}$ \\
3 & Accelerated test load factor & $k$ & 2.2 \\
4 & Acceleration due to gravity & $\mathrm{g}$ & $10 \mathrm{~m} / \mathrm{s} 2$ \\
5 & Tire pressure & $p$ i & $303.4 \mathrm{kPa}$ \\
6 & Element type & SOLID 187 & SOLID 187 \\
\hline
\end{tabular}

In finite element analysis, the software uses iterative methods to calculate the result at some selected boundaries, primarily the result calculated are elemental as well as nodal results. The governing equations are solved at these nodes. Generally, during this analysis process, the primary solution output is the displacement at the nodal points. However, other derived results such as stresses can also be obtained for the analysis at different nodal points. In this analysis, the static stress distribution is needed to perform the fatigue life prediction of the wheel assembly.

To estimate the true endurance limit at the critical location of the wheel disc $\left(\mathrm{S}_{\mathrm{e}}\right)$, a mathematical model reported by Budynas [9] was used. The endurance limit was estimated to be $\leq 154.76 \mathrm{MPa}$ and $\geq 142.26 \mathrm{MPa}$. A fatigue failure criterion for the fluctuating stress was also identified, which tends to affect the true fatigue endurance limit for the wheel component, thus, reducing the fatigue life. Using the same proposal by Budynas [9] the factors were determined to correct the fatigue endurance limit for the critical loading. The mean stress correction factor used is based on the Gerber theory. The constant amplitude loading generated from the simulation is shown in Figure 4 below.

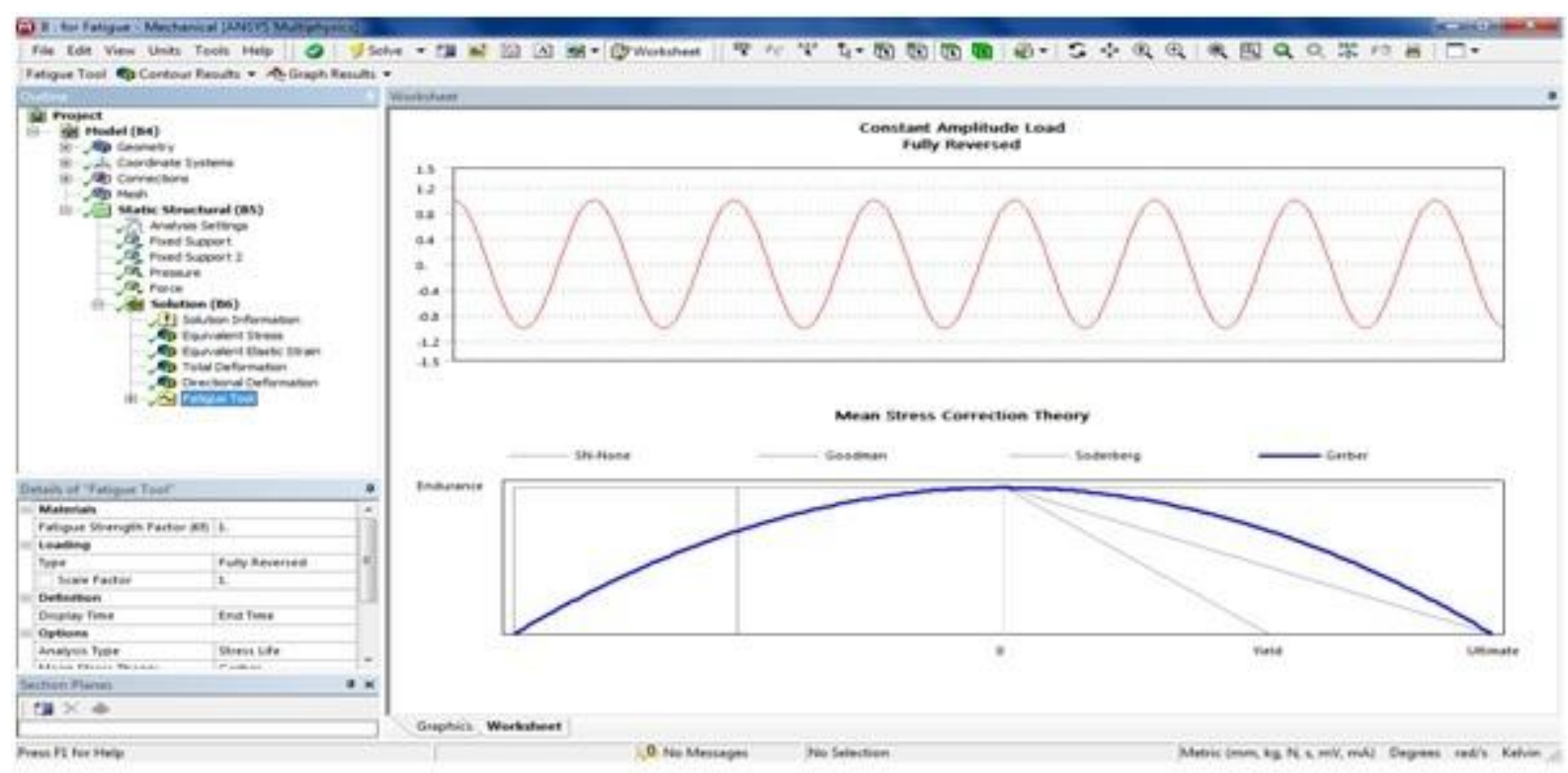

Figure 4. Constant amplitude loading and Mean Stress Correction Factor

The stress life method of fatigue analysis involves the use of a Wohler S-N diagram to deduce the corresponding fatigue life at a given alternating stress amplitude on the plot. Thus, the S-N curve used in this analysis has been obtained by using empirical formulas report by Schijve [10] and comparing with the traditional S-N curve for a rotating steel beam specimen. Using interpolation the S-N curve was then applied to the ANSYS Workbench.

\section{III.1. Static Study}

\section{Result And Discussion}

From the finite element software, the result of the Von Mises stress distribution obtained from the static stress analysis is as shown in Figure 5. It shows that the maximum Von Mises stress occurred at the wheel forks. The region has a stress concentration due to non-uniformities and therefore, stress concentration factor.

This analysis did not include the fillets at the wheel when determining the mathematical model. This was to avoid unnecessary factors that would negatively affect the result.The computational resources are also maximized when the geometry to be used for analysis is fully prepared to reflect actual geometries of the model and not fillets. 


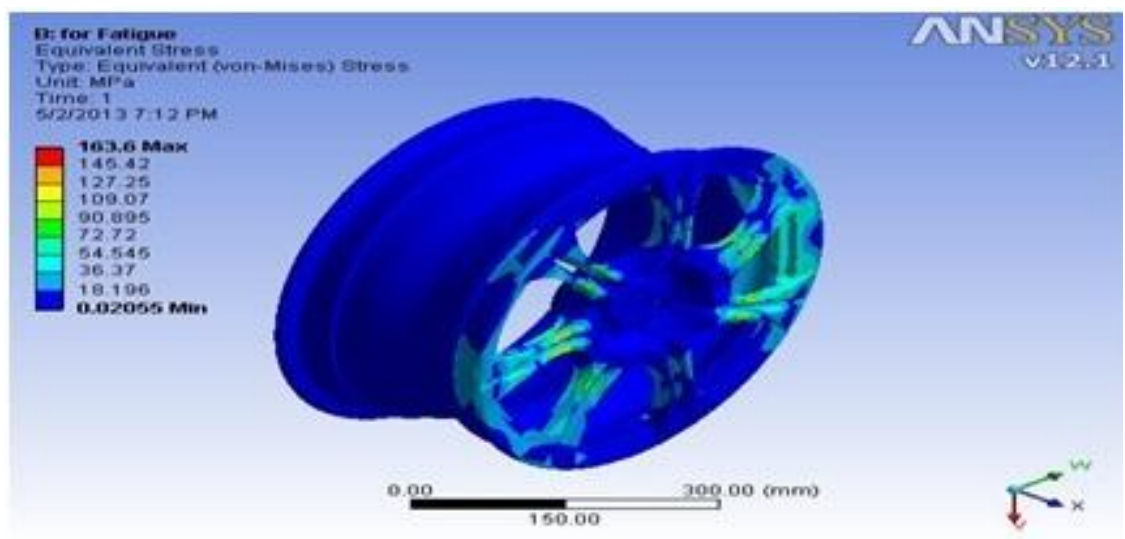

Figure 5.Von Mises Stress distributions on the wheel

The point of maximum stress concentration factor as obtained from Figure 5 was used to determine the maximum stress, given as $\sigma_{\max }=163.6 \mathrm{MPa}$. This fatigue failure observed may be caused by the alternation of the stresses as the wheel rotates.

\section{III.2. Fatigue Study}

During the static analysis of the steel wheel, it was discovered that the maximum stress concentration $\left(\sigma_{\max }\right)$ occurred at the spokes and ventilation hole of the rim under loads Fr and pi. This point of maximum stress concentration was found to be identical with that of actual practical test results. The wheel rotating at a speed of $1790 \mathrm{rpm}$ under the stated loads, fatigue crack propagation at the point of maximum stress concentration is observed as demonstrated in Figure 6.In addition, Figure 7 also shows the maximum deflection (deformation) of the wheel under the same loading conditions.

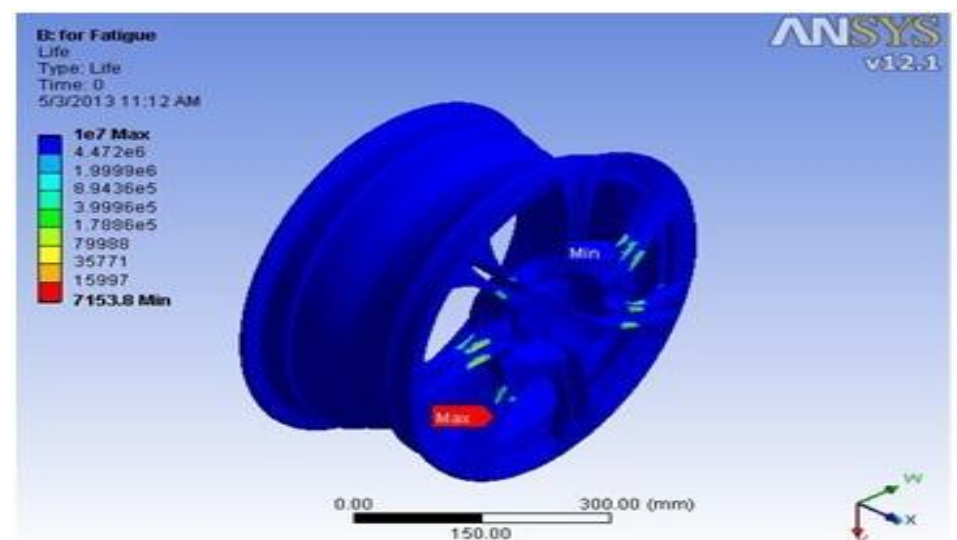

Figure 6. Fatigue life estimations at the critical region of the air ventilation hole for $k e=0.535$
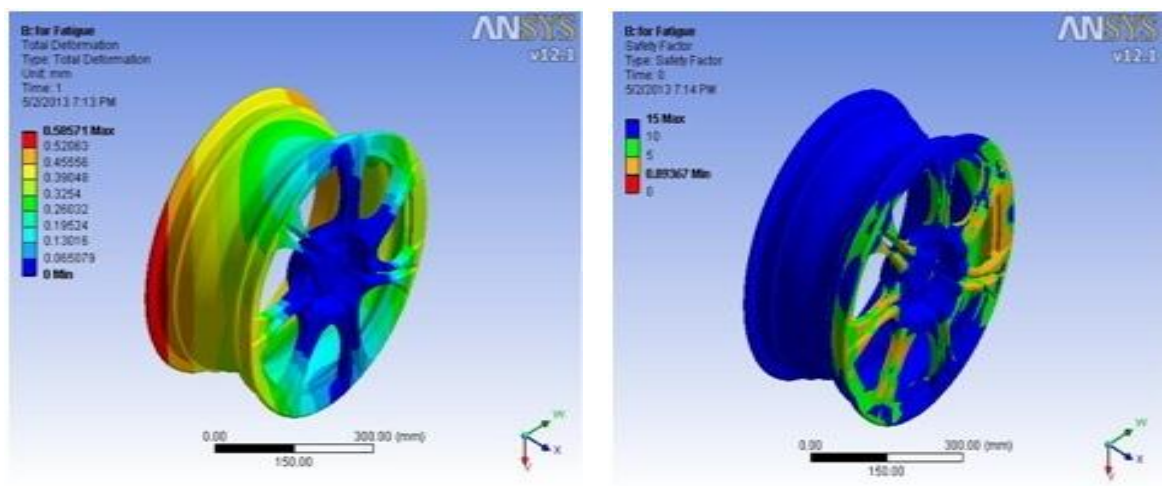

Figure 7. Deflection of the Rim in mm and Factor of Safety 
Figure 8 shows the range of the equivalent alternating stress used for the analysis of the fatigue stress correction factor. This was necessary in order to obtain the maximum number of cycles the wheel will undergo before failure.

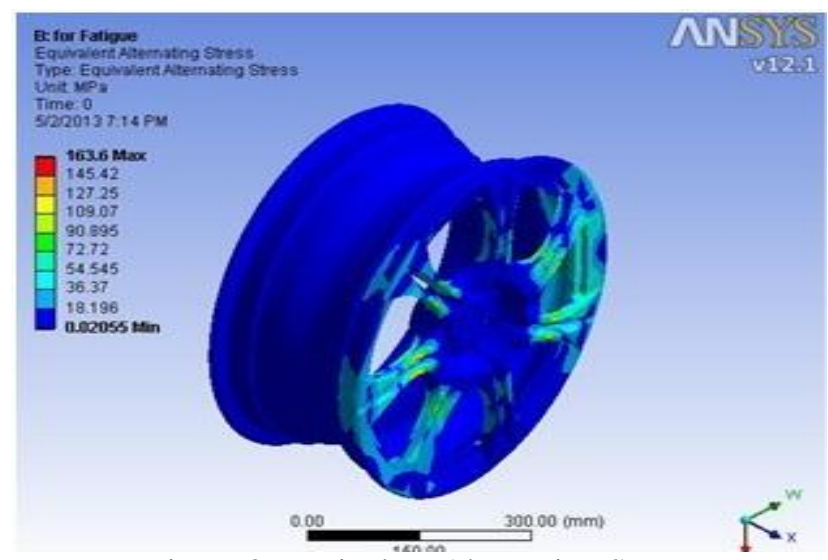

Figure 8. Equivalent Alternating Stress

\section{Conclusion}

The finite element based approach, using ANSYS, is an effective method of predicting the failure mode of an automobile wheel during the wheel design stage. Finite element-based stress analysis and fatigue life prediction obtained from the ANSYS software showed that the fatigue crack initiation regions on the wheel are subjected to stress concentration. Fatigue crack initiation occurs at the most stress concentrated regions of the wheel spokes and air ventilation holes which are the critical regions of the wheel. The predicted failure locations are identical to the actual crack initiation regions and are consistent with order reports [5].

\section{Acknowledgement}

The authors would like to thank the Niger Delta University for providing the facilities for this project.

\section{Reference}

[1] Courtney, T.H. (2005), Mechanical behavior of materials. Long Grove, IL: Waveland Press, Inc

[2] Callister, J.R. (2008), Fundamentals of materials science and engineering: an integrated approach, Hoboken NJ: Waveland Press, Inc

[3] Kocabicak, U. and Firat, M.(2001) Numerical analysis of wheel cornering Fatigue tests, Engineering Failure Analysis 8, pp339-354

[4] Lu, S., Wei, W., Yu, L., Jiang, Y., Tan, J. and HongQiang, R. (2011), Fatigue life analysis of aluminum HS6061-T6 rims using finite element method," Remote Sensing, Environment and Transportation Engineering (RSETE), International Conference on , vol., no., pp.5970,5973, 24-26, doi: 10.1109/RSETE.2011.5965715

[5] Wang, L., Chen, Y., Wang, C. and Wang, Q. (2011), Fatigue Life Analysis of Aluminum Wheels by Simulation of Rotary Fatigue Test, Journal of Mechanical Engineering 571, pp 31-39, DOI:10.5545/sv-jme.2009.046

[6] Topaç, M. M., Günal H, and Kuralay N.S. (2009), Fatigue failure prediction of a rear axle housing prototype by using finite element analysis, Engineering Failure Analysis 16 (5),pp1474-1482

[7] Torgal, S. and Mishra, S. (2012), Stress Analysis of wheel rim, International Journal of Mechanical Engineering and Research, Vol. 1, pp34-37.

[8] EUWA-Association of European Wheel Manufacturers (2006), Biaxial Test requirements for truck steel wheels, EUWA standards, ES 3.11. http://www.euwa.org/images/auto/euwa std 311.pdf(Last visited 10 ${ }^{\text {th }}$ January 2014)

[9] Budynas, N., (2006),Shigley's Mechanical Engineering Design, 8th edition,McGrawHill, New York

[10] Schijve, J. (2001) Fatigue of structures and materials. Dordrecht: Kluwer Academic Publishers, pp144-172. 